\title{
Increased performance of thin-film GaAs solar cells by rear contact/mirror patterning
}

\author{
N. Gruginskie*, S.C.W. van Laar, G. Bauhuis, P. Mulder, M. van Eerden, E. Vlieg, J.J. Schermer \\ Radboud University, Institute for Molecules and Materials, Applied Materials Science, Heyendaalseweg 135, 6525 AJ Nijmegen, The Netherlands
}

\section{A R T I C L E I N F O}

\section{Keywords:}

Gallium arsenide

Thin-film solar cells

Photon recycling

Rear mirror

\begin{abstract}
A B S T R A C T
Current thin-film GaAs solar cells typically have a completely metal covered rear side that functions as back contact, rear mirror and stable carrier to the solar cell. However, the bottom contact layer, that typically remains whole in this configuration, absorbs a large amount of photons that would otherwise be reflected back into the cell structure. This work identifies and quantifies the performance limits by non-optimal rear contact reflectance in the standard configuration of thin-film GaAs solar cells and proposes a design solution. In this study we show that the total reflectance at the back of the solar cell is increased from $63.5 \%$ to $93.2 \%$ by partially etching the absorbing GaAs contact layer and applying a dielectric material in the etched regions. Both shallow junction and deep junction cells were produced, and for deep junction solar cells the patterning resulted in a more than linear increase in the open circuit voltage and a linear increase in the short circuit current, which is in good agreement with previously reported numerical models.
\end{abstract}

\section{Introduction}

Most III-V materials used for solar cells, such as GaAs and InGaP, are semiconductors with direct bandgap and high absorption coefficients, therefore only few micrometers thick devices are required to absorb all the incident light. However, in order to obtain good quality single crystal solar cell structures, the materials have to be grown epitaxially on top of a GaAs or Ge wafer, with thicknesses that typically vary from $100 \mu \mathrm{m}$ to $650 \mu \mathrm{m}$. After the growth, the wafer is of no value for the cell performance and it can be removed from the growth structure without any detrimental effect on the efficiency.

Methods to remove the growth template wafer of GaAs solar cells, such as epitaxial lift-off (ELO), produce as final result thin-film devices that can be semitransparent or, more commonly, mounted on a metal foil that works as stable flexible handler and rear contact [1-11]. In the latter configuration, the rear contact also acts as mirror to the incident light, enabling cells to have even smaller thicknesses (of around $2 \mu \mathrm{m}$ ). This thin-film geometry is superior to those of cells processed on the native wafer and have reached higher world record efficiencies [12].

It has been demonstrated that GaAs solar cells can potentially operate close the Shockley-Queisser efficiency limit [13-16] mainly by optimizing the optical advantages of the thin-film geometry. These advantages hold large promises for the applicability of these devices in space applications [17], concentrating solar systems and in combination with third generation photovoltaics.
In thin film-configurations, the production costs can be reduced with wafer reuse. Another major contribution to the cost is the growth of epitaxial structures, and this can be diminished with the production of thinner devices. For ultrathin cells (with few hundred nanometers of thickness), however, not all the incident light can be absorbed and even though these devices can be rapidly grown, it requires the application of nanostructures in the front and rear side. But to date the efficiencies achieved with solar cells of a few hundred nanometers in thickness are still relatively low (below 17\%) [18-21]. This indicates that the effective increase in the optical path length of the light captured by the use of gratings and nanostructures has not yet been sufficiently implemented to compensate for drastic reductions in thickness.

The standard design of GaAs solar cells consists of a thin n-doped emitter and thicker p-doped base, here called a shallow junction (SJ) solar cell. With high quality materials, however, the minority carrier diffusion length of the emitter is improved. This allows the production of deep junction (DJ) devices, with thick emitter and thin base, that are able to achieve higher performances, as they operate mainly in the radiative recombination regime at the maximum power point [22]. As the current world-record efficiency of $28.8 \%$ for a single junction thinfilm GaAs solar cell was achieved in 2012 [12] and has not been surpassed to date, these cells are clearly approaching the limit in material quality. In these cases, radiative recombination becomes the dominant loss mechanism [23-25], and photon recycling has been indicated to be the most important process in order to achieve higher $\mathrm{V}_{o c}$ values in

\footnotetext{
" Corresponding author.

E-mail address: n.gruginskie@science.ru.nl (N. Gruginskie).
} 


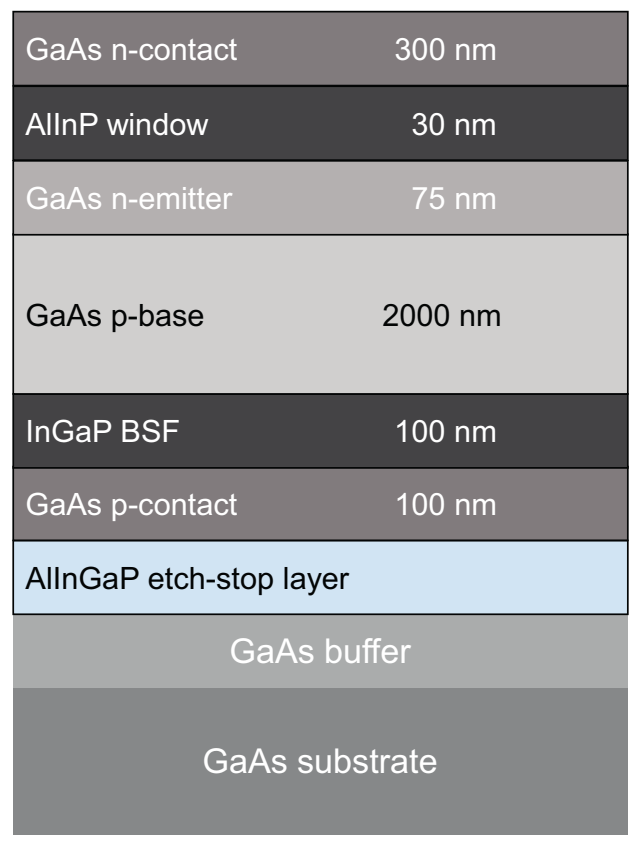

(a)

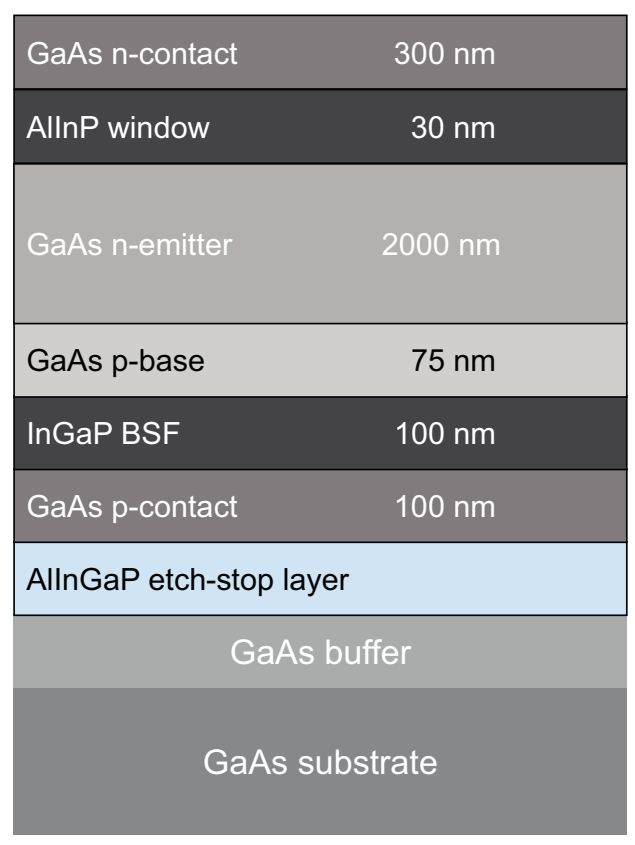

(b)

Fig. 1. Schematic representation of the a) shallow junction (SJ) and b) deep junction (DJ) solar cells processed in this study (not to scale).

previous world record cells [26]. Therefore, confining reemitted photons inside the active layers of the cell becomes fundamental in order to achieve efficiencies closer to the theoretical limit [15,16,27-29].

In the present study we evaluate the behavior of emitted photons in the rear layers of GaAs thin-film solar cells and the role of the rear contact design on the reflectance and photon recycling. Devices with both shallow junction and deep junction configuration were produced with increased reflectance of the rear surfaces, and the effects on the cell key parameters from these changes in the rear contact layout were evaluated.

\section{Methods}

The solar cells used in this study were grown using low-pressure MOCVD on 2 in. diameter GaAs wafers with $\left(\begin{array}{llll}1 & 0 & 0\end{array}\right) 2^{\circ}$ off to $\left[\begin{array}{lll}1 & 1 & 0\end{array}\right]$ orientation. The grown cell structures are shown in Fig. 1. In this study the wafer was removed by chemical etching with an aqueous citric acid and hydrogen peroxide solution (5:1 in volume), instead of using the more elaborative epitaxial lift-of method. In order to control the fragile thin-film single crystal structures, the front surface of the solar cells were mount to a etch-resistant temporary plastic carrier. To stop the process after etching of the wafer, a thin AlInGaP etch-stop layer was grown before the solar cell structure. Subsequently, the etch-stop layer was removed in a $37 \% \mathrm{HCl}$ solution.

Using photolithography a pattern of disk-shaped contact areas was created in the GaAs rear contact layer. In between these contact areas with diameters ranging from $260 \mu \mathrm{m}$ to $580 \mu \mathrm{m}$ the p-GaAs contact layer was etched away using an $\mathrm{NH}_{4}: \mathrm{H}_{2} \mathrm{O}_{2}: \mathrm{H}_{2} \mathrm{O}(1: 2: 10)$ solution, resulting in cells with four different rear surface contact area coverages $\left(C_{r}\right)$ of $100 \%, 50 \%, 30 \%$ and $10 \%$. Next, a $60 \mathrm{~nm}$ thick $\mathrm{ZnS}$ insulating layer was deposited by thermal evaporation before removal of the photoresist, so that finally the ZnS covers only the etched regions. Then a $200 \mathrm{~nm}$ Au layer was deposited by e-beam evaporation throughout the entire rear surface to promote ohmic contact at the contact areas and simultaneously act as a high quality reflector at the rest of the area, followed by a thick electroplated Cu layer, to facilitate handling of the sample.

The temporary plastic carrier was removed from the front surface and a $200 \mathrm{~nm}$ thick Au front grid contact was deposit by e-beam evaporation. For convenience during processing and cell analysis, a grid pattern with a relatively large front surface coverage $\left(\mathrm{C}_{f}\right)$ of $16.6 \%$ was applied for most cells. One or two cells in each configuration were created with a square frame-like contact pattern and without grid fingers, which is ideal for optical analysis. The n-contact layer was removed in between the metal contact areas using an $\mathrm{NH}_{4}: \mathrm{H}_{2} \mathrm{O}_{2}: \mathrm{H}_{2} \mathrm{O}$ (2:1:10) solution and the $25 \mathrm{~mm}^{2}$ cells were defined by a mesa-etch with a $\mathrm{HBr}: \mathrm{Br}_{2}: \mathrm{H}_{2} \mathrm{O}(100: 1: 200)$ solution for phosphide layers and an $\mathrm{NH}_{4}: \mathrm{H}_{2} \mathrm{O}_{2}: \mathrm{H}_{2} \mathrm{O}$ (1:2:10) solution for GaAs layers. Finally, an anti-reflection coating consisting of $44 \mathrm{~nm}$ of $\mathrm{ZnS}$ and $94 \mathrm{~nm}$ of $\mathrm{MgF}_{2}$ was deposited by thermal evaporation. The resulting thin-film with multiple solar cells as well as a schematic depiction of the pattern applied to the contact layer are shown in Fig. 2. In contrast to the processing of wafer based cells, the processing of thin-film geometry is less well developed, but for each $C_{r}$ value (i.e. from each quarter of the thin-film) 3 to 5 operating cells were obtained.

I-V characterization of the solar cells is performed using an ABET Technologies Sun 2000 Class AAA solar simulator, which provides a uniform illumination resembling the AM1.5G spectrum, over a $100 \times 100 \mathrm{~mm}^{2}$ area, with a maximum angular off set of $2^{\circ}$. The setup is equipped with a Keithley $2601 \mathrm{~B}$ source meter and data acquisition is performed using ReRa Tracer3 software. The solar cells are kept at $25^{\circ} \mathrm{C}$ during measurement using a heating/cooling water thermostat and Pt100 temperature sensing.

The setup is calibrated using an NREL calibrated reference cell before each measurement series. Using this approach the cell parameters can be retrieved from the I-V curves with a systematic error of $\pm 3 \mathrm{mV}$ in $V_{o c}, \pm 0.8 \mathrm{~mA} / \mathrm{cm}^{2}$ in $J_{s c}$ and \pm 0.005 in FF compared to an absolute reference. In mutual comparison the trends in the performance of cells as a consequence of deliberate changes in the cell geometry can be identified with an accuracy of $\pm 2 \mathrm{mV}$ in $V{ }_{o c}, \pm 0.06 \mathrm{~mA} / \mathrm{cm}^{2}$ in $J_{s c}$ and \pm 0.003 in $\mathrm{FF}$.

External Quantum Efficiency (EQE) measurements are performed with a ReRa SpeQuest Quantum Efficiency system. The system uses both a Xenon and Halogen light source to address all wavelengths present in the solar spectrum. A monochromator is used to generate quasi-monochromatic light and a chopper for intensity modulation. 


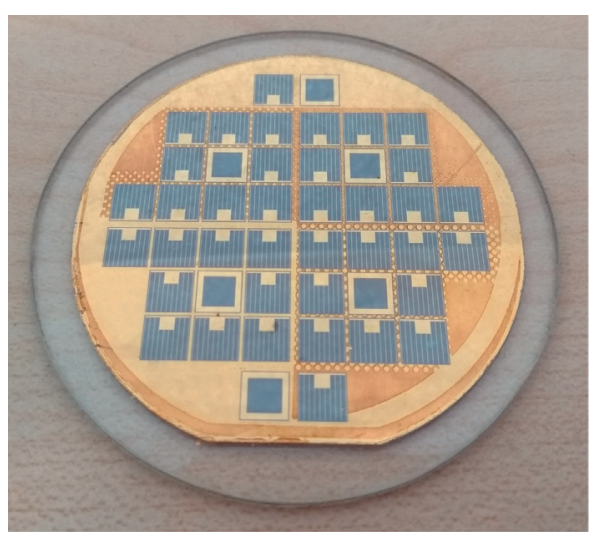

(a)

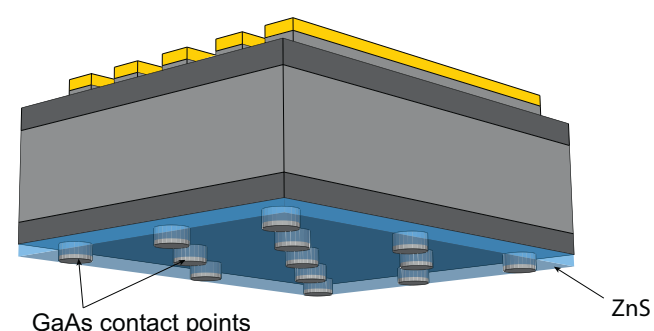

GaAs contact points

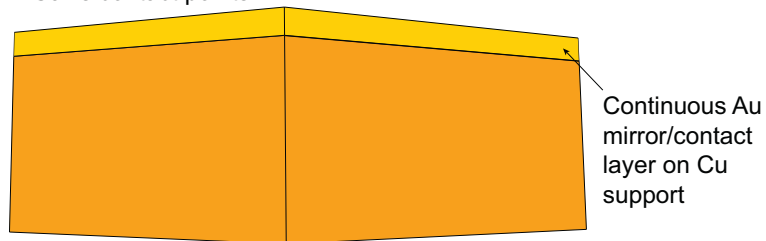

(b)

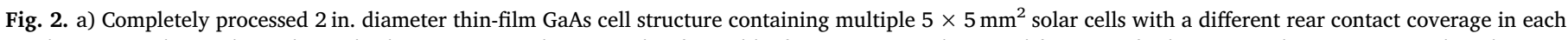

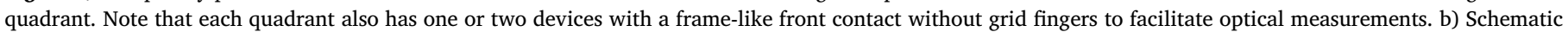
representation of the rear contact pattern design (not to scale).

This generates a test light of variable wavelength while a continuous bias light and bias voltage is used to put the cell under test in operating conditions.

The reflectance calculations were made using the transfer matrix method considering only normal incidence of photons. The required $n$ and $\mathrm{k}$ values for GaAs and Au were retrieved from the SOPRA database [30]. For $\mathrm{ZnS}, \mathrm{MgF}_{2}$ and $\mathrm{InGaP}$ these data were retrieved from elipsometry analyses of test samples (typically $100 \mathrm{~nm}$ of the material on a GaAs substrate) that were prepared under the same conditions as the corresponding layers in our solar cell structures. Reflectance measurements were performed with a FilMetrics spectrophotometer perpendicular to the analyzed surfaces, using a gold mirror for calibration.

\section{Results and discussion}

\subsection{Photon absorption in the GaAs back contact layer}

In order to create good ohmic contacts, the first and last grown layers in thin-film GaAs solar cells are usually highly doped GaAs contact layers. At the front side of the cell this layer is removed in between the grid fingers, but for the rear contact, it typically remains whole. Even though the contact layer is relatively thin $(100 \mathrm{~nm})$, a relevant fraction of available photons is absorbed in it. This is because photons emitted in the active layers of the cell as a result of band-toband recombination are repeatedly reflected inside the cell structure and pass through the contact layer several times. Fig. 3 depicts the calculated reflectance at the rear side interfaces of the thin film cell $\left(\mathrm{R}_{G a A s / A u}\right)$ considering normal incidence of photons. At room temperature, band-to-band emissions from GaAs peak at around $870 \mathrm{~nm}$ (the band-gap wavelength), and the full-width at half maximum (FWHM) of the emission line is $28 \mathrm{~nm}$. The emissions from GaAs cease at the bandgap, so the reflectance should be maximized in the region between $870 \mathrm{~nm}$ and $840 \mathrm{~nm}$ [31]. At these wavelengths, the calculations show a large absorption ( $>30 \%$ ) of generated photons, with an average reflectance of $63.5 \%$ in this region. In a structure without a GaAs contact layer, the reflectance $\left(R_{A u}\right)$ could be increased to approximately $94 \%$.

Absorbed photons in the non-active layers of the cell are lost as they do not contribute to the cell performance. Therefore, it will be beneficial to partially remove the rear contact layer, analogous to the procedure applied at the front side. If a transparent insulator material is deposited in the areas where the contact layer is removed and Au remains deposited continuously at the rear surface, at the etched regions the Au layer will function only as a mirror. The benefit of the intermediate layer is that a certain fraction of the light is already reflected at the semiconductor-dielectric interface before reaching the gold interface that because of its higher extinction coefficient does represent some absorption losses. The thickness of the dielectric layer can be tuned in such a way that in the relevant wavelength range corresponding to the GaAs bandgap in the fraction reflected at the gold interface is minimal due to destructive interference.

The materials considered for the transparent insulator layers were $\mathrm{ZnS}$ and $\mathrm{MgF}_{2}$, both with a refractive index in between that of InGaP $(\mathrm{n}=3.2)$ and gold $(\mathrm{n}=0.2)$ at the $870 \mathrm{~nm}$ wavelength region. Fig. $4 \mathrm{~b})$ and c) shows the wavelength dependent reflectance following from simulations performed using the layer structure in Fig. 4a, with the dielectric materials instead of the contact layer. The simulations show an increase in reflectance if either $\mathrm{ZnS}$ or $\mathrm{MgF}_{2}$ is applied before the $\mathrm{Au}$ layer as compared to Au directly applied to the back surface field. According to these simulations, the use of $\mathrm{MgF}_{2}$ will result in the highest reflectance. In practice, however, the adhesion from the thermally evaporated $\mathrm{MgF}_{2}$ to the semiconductor material was found to be problematic, as it easily delaminates. Therefore, $\mathrm{ZnS}$ was the chosen material for further studies.

In the first place the role of the rear mirror in thin-film solar cells is to reflect the incident light that is not absorbed in the first pass. This enhances overall absorption and increases the short-circuit current density $\left(J_{s c}\right)$ or alternatively allows to reduce the active cell layer thickness without loss in $J_{s c}$. GaAs is a good absorbing material, and in the produced $2 \mu \mathrm{m}$ thick solar cells most of short wavelength light is absorbed in the first pass through the active layers, and the rear mirror reflectance is particularly important for wavelengths above $700 \mathrm{~nm}$. In the second place the rear mirror is important to confine photons that are emitted upon radiative carrier recombination with wavelengths between $840 \mathrm{~nm}$ and $870 \mathrm{~nm}$, so they can be reabsorbed in the active layers of the structure. This increase in the photon recycling will result in an increase in the open circuit voltage $\left(V_{o c}\right)[14,16]$.

Experimental measurements were made to confirm the increase in reflectance obtained by the deposition of $\mathrm{ZnS}$. For this purpose, $650 \mu \mathrm{m}$ thick GaAs wafers polished on both sides were used. An ARC optimized for longer wavelengths was deposited on the front surface and different thicknesses of $\mathrm{ZnS}$ ranging from 0 to $100 \mathrm{~nm}$ were evaporated on the rear surface, which were subsequently covered with $200 \mathrm{~nm}$ of $\mathrm{Au}$. These structures and the obtained reflectance curves are depicted in Fig. 5. Because of the long optical path that the light has to travel in the GaAs wafer, it is not possible to measure the reflectance mechanisms in the bandgap region. However, a comparative analysis of the different interfaces can be done by observing the reflectances at slightly longer wavelengths. Even though parasitic sub-bandgap absorption in the 


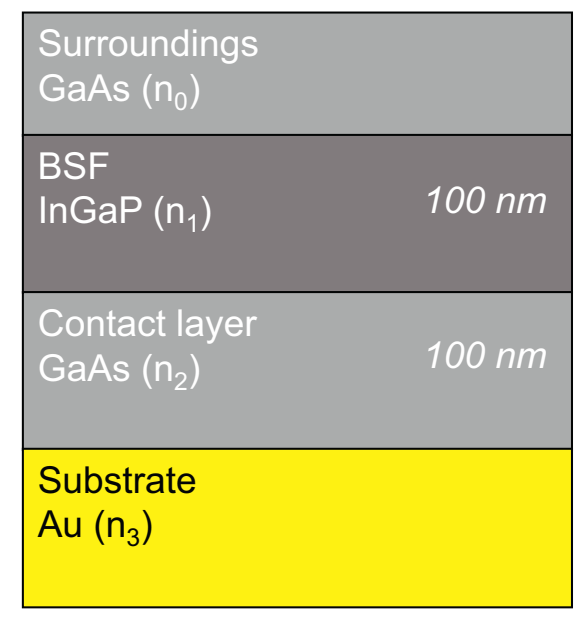

(a)

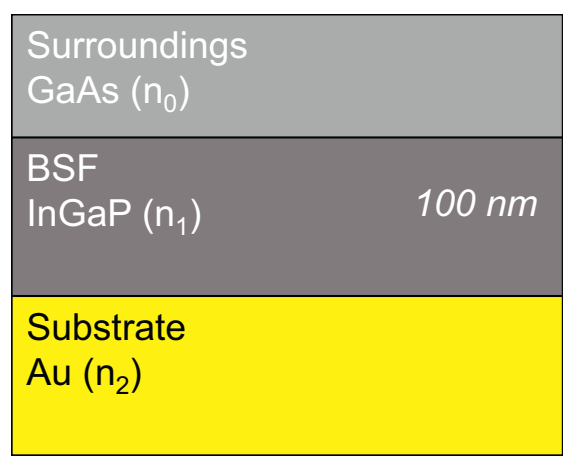

(b)

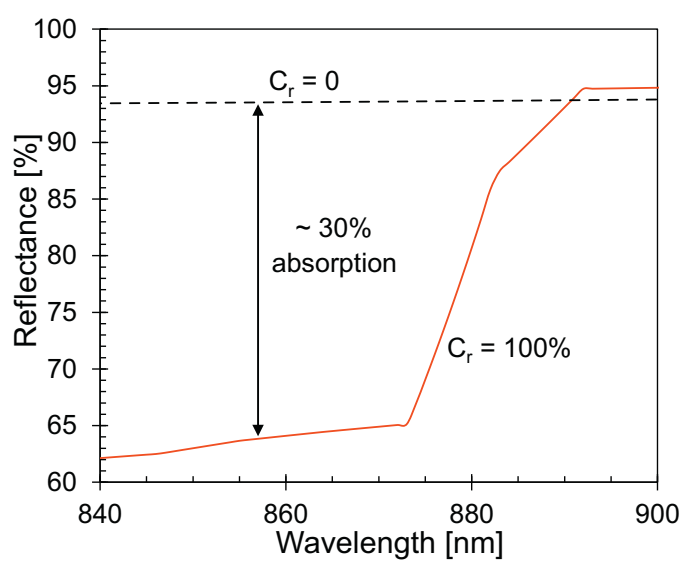

(c)

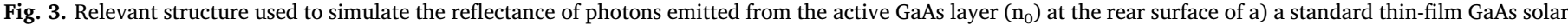

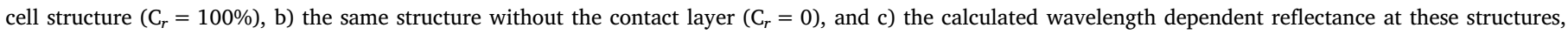
considering normal incidence of photons.

$650 \mu \mathrm{m}$ thick GaAs substrate cause the absolute reflectance values to be different from the simulations, at around $1050 \mathrm{~nm}$ both simulated and measured curves show similar patterns, confirming the increase in reflectance caused by the deposition of ZnS.

The deposition of $100 \mathrm{~nm}$ of $\mathrm{ZnS}$ would result in highest reflectance at wavelengths above the bandgap, but the calculated average reflectance between $840 \mathrm{~nm}$ and $870 \mathrm{~nm}\left(\mathrm{R}_{Z n S}\right)$ is equal to $96.5 \%$ for both $60 \mathrm{~nm}$ and $100 \mathrm{~nm}$ of $\mathrm{ZnS}$. For shorter wavelengths (important to avoid $J_{s c}$ losses), however, the reflectance of $60 \mathrm{~nm}$ of $\mathrm{ZnS}$ is higher than for $100 \mathrm{~nm}$. Therefore, $60 \mathrm{~nm}$ was the thickness of $\mathrm{ZnS}$ applied to the produced devices.

\subsection{Rear contact patterning to improve the reflectance}

From the previous evaluation it is clear that, compared to the p$\mathrm{GaAs} / \mathrm{Au}$ structure, the $\mathrm{ZnS} / \mathrm{Au}$ structure has an improved reflectance of photons in the relevant wavelength range $(840-870 \mathrm{~nm})$ to the active layers cells (approximately 63.5\% compared to 96.5\%). Therefore the reflectance at the rear side of thin-film GaAs solar cells can be improved by reducing $\mathrm{C}_{r}$ and with the application of an intermediate $\mathrm{ZnS}$ layer. To evaluate this experimentally, cells with four different rear contact geometries $\left(\mathrm{C}_{r}=100 \%, 50 \%, 30 \%\right.$ and $\left.10 \%\right)$ were produced simultaneously from a single wafer (see Fig. 2). In this way, any performance variation observed between the solar cells can unambiguously be assigned to the rear side patterning, rather than eventual small run to run differences in wafer processing. The electroluminescence images of the thin-film cells, shown in Fig. 6, clearly reflect the rear side contact geometry of the devices, as this technique injects current in the solar cells through the contacts, leading to radiative recombination in the active area. Because the current density is highest in the direct vicinity of the contact areas, these are brighter due to higher recombination rates. The obtained contact pattern is well defined and there is no apparent defect formation resulting from the patterning.

As first order approximation, the average rear side reflectance in the wavelength range from 840 to $870 \mathrm{~nm}$ of the cells with different $\mathrm{C}_{r}$ values can be determined by $R_{\text {cell }}=C_{r} \cdot R_{G a A s / A u}+\left(1-C_{r}\right) \cdot R_{Z n S / A u}$. This approximation yields values of $63.5 \%, 80.0 \%, 86.6 \%$ and $93.2 \%$ for $\mathrm{C}_{r}=100 \%, 50 \%, 30 \%$ and $10 \%$ respectively. The total reflectance of the processed DJ cell structures without grid fingers, measured using a spectrophotometer perpendicular to the cell front surface, are shown in Fig. 7. Similar as calculated above for the photons in the $840-870 \mathrm{~nm}$ range, photons with wavelengths above this range show enhanced reflectance as $\mathrm{C}_{r}$ is reduced and the area covered with $\mathrm{ZnS}$, beneficial to the reflectance, is increased. However, the absolute value of the reflectance for these photons is higher because they do not suffer from absorption in the GaAs rear contact layer. Unfortunately, the solar cell without grid fingers with $\mathrm{C}_{r}=50 \%$ was damaged, and therefore there is no reflectance spectrum for this configuration.

The illuminated IV parameters under 1 sun conditions of the best performing cells in both the SJ and DJ set of devices with different $\mathrm{C}_{r}$ 


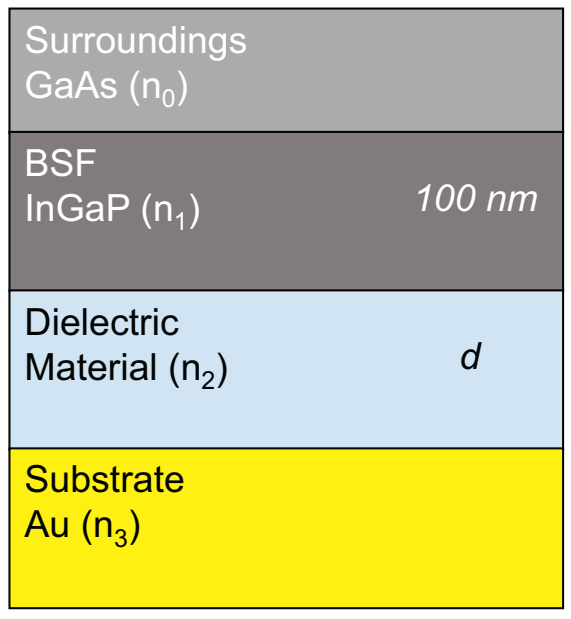

(a)

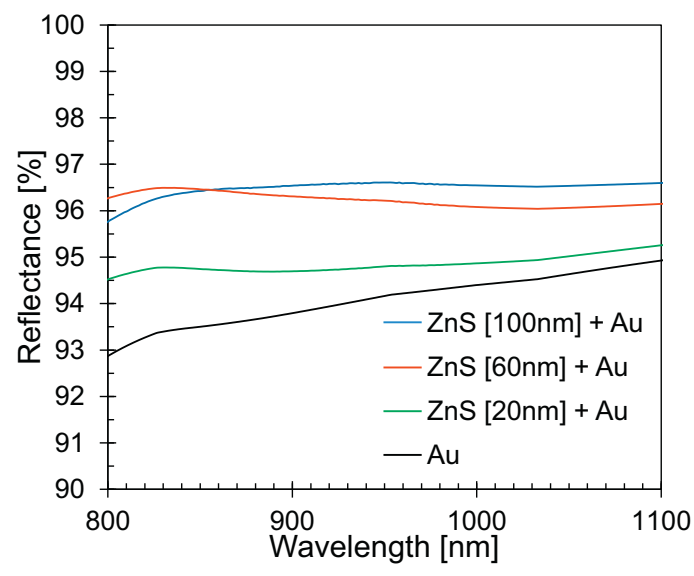

(b)

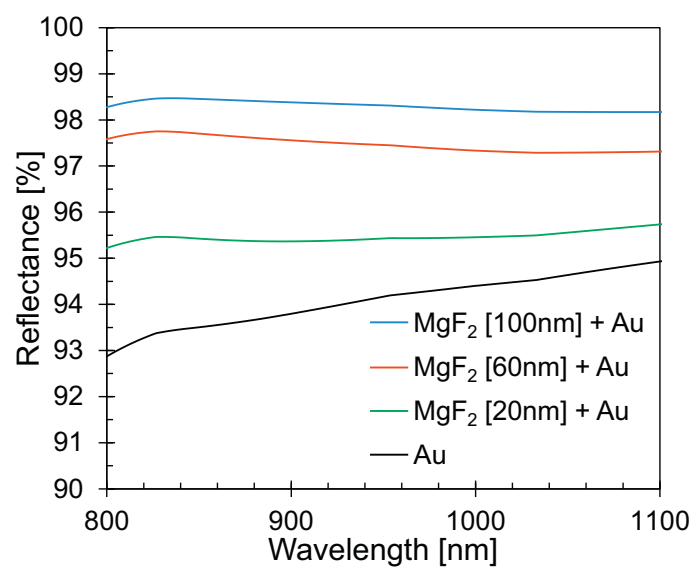

(c)

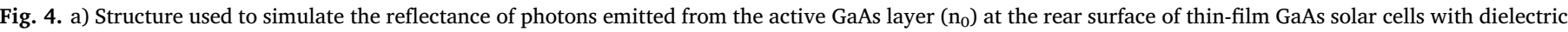

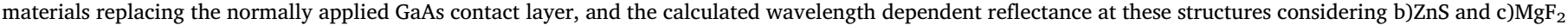
as the dielectric materials.

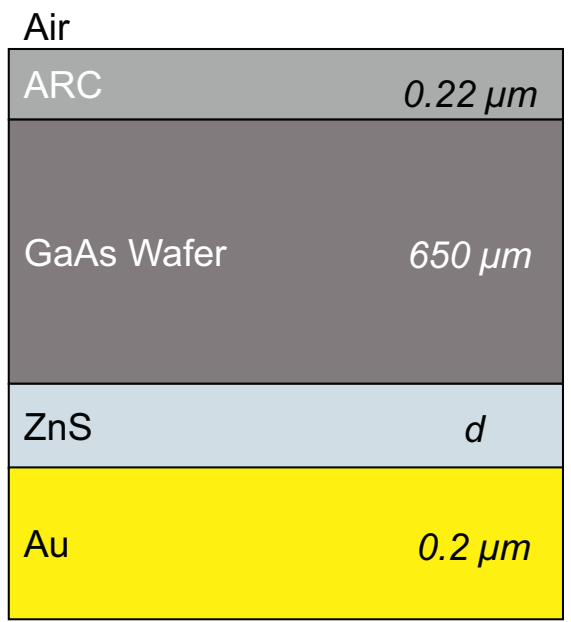

(a)

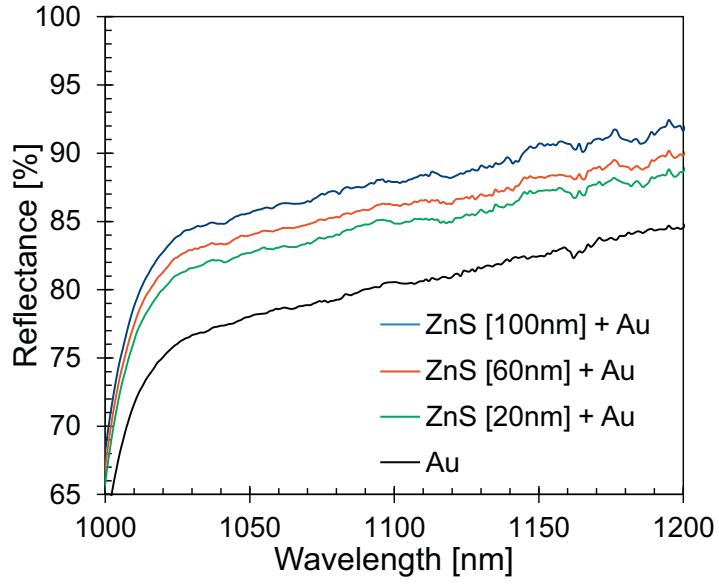

(b)

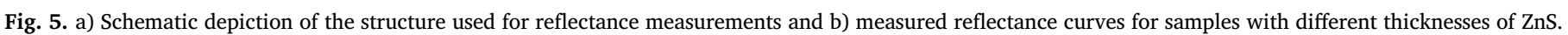




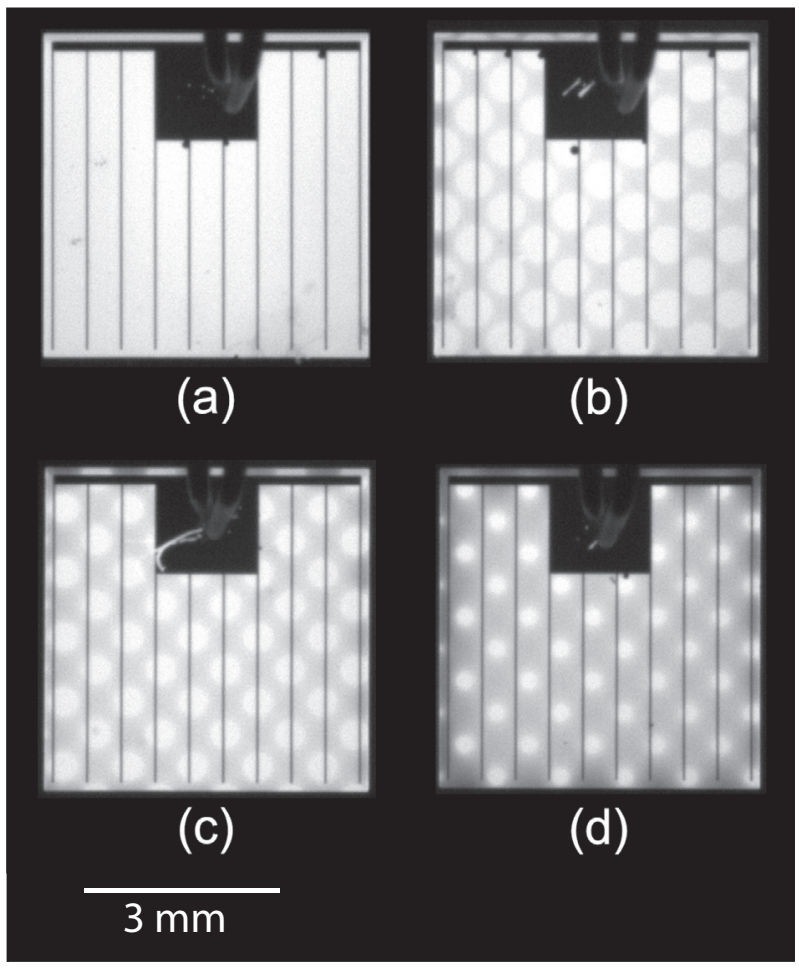

Fig. 6. Electroluminescence images of the cells with $\mathrm{C}_{r}$ equals to a)100\%, b) $50 \%, c) 30 \%$ and d) $10 \%$. The camera parameters and the applied current were kept constant for all measurements.

values are shown in Table 1 . For the SJ devices, $\mathrm{C}_{r}=50_{r}=50 \%$ was not applied and there are no results for this geometry. In the SJ devices, the $J_{s c}$ remained constant, but both the $V_{o c}$ and the FF values decrease as $\mathrm{C}_{r}$ decreases, and no advantages were observed with the patterning. In the DJ configuration, both $J_{s c}$ and $V_{o c}$ increase for lower $C_{r}$ values. The FF of the cells essentially stays constant only to drop suddenly by more than $3 \%$ for $\mathrm{C}_{r}=10_{r}=10 \%$, most probably by an increase in series resistances related to the strongly reduced rear contact area. In these samples, the thick and continuous rear contact reduces metal contact resistances to a negligible value, indicating that the main loss mechanism is the lateral resistance that carriers encounter from the position they are generated to the contact points. An optimized design with more evenly dispersed smaller contact points for the rear contact is expected to reduce the fill factor losses considerably, thus allowing for the production of devices with even lower $\mathrm{C}_{r}$.

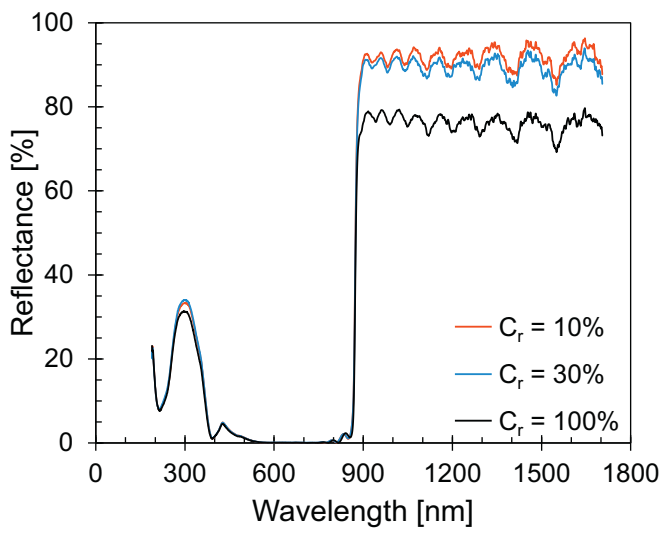

(a)
The differences in performances between SJ and DJ devices are explained with the analysis of the dark curve. The diode recombination current density is described by [26]:

$J_{\text {rec }}=J_{01}\left(e^{\frac{q V}{k T}}-1\right)+J_{02}\left(e^{\frac{q V}{2 k T}}-1\right)$

with $n=1$ the radiative and $\mathrm{n}=2$ the non-radiative recombination ideality factors. The non-radiative recombination is known to predominantly take place in the depletion zone and the perimeter of the cell, while the radiative recombination is dominant in the neutral regions of the cell. For DJ cells at operating voltage, the contribution of non-radiative recombination is lower than for SJ cells [22]. The ratio between the recombination currents is voltage dependent, with nonradiative recombination dominating $J_{r e c}$ at low voltages and radiative recombination at higher voltages. In the analysis of the dark current at lower voltages of the produced samples with $\mathrm{C}_{r}=100 \%$ we find that the non-radiative saturation current density $\left(J_{02}\right)$ is one order of magnitude higher for the SJ devices $\left(3 \times 10^{-11} \mathrm{~A} / \mathrm{cm}^{2}\right)$ compared to the DJ geometry $\left(4.8 \times 10^{-12} \mathrm{~A} / \mathrm{cm}^{2}\right)$. At the operating voltage, $J_{\text {rec }}$ of the SJ cell is therefore mostly non-radiative and consequently the application of an improved geometry for photon recycling in these cells has no noticeable effect on the cell performance.

A $J_{s c}-V_{o c}$ curve composed of data points of I-V curves measured under different light intensities represents the ideal diode dark characteristics, as the series resistance is excluded under these conditions [32]. At higher voltages (the $\mathrm{n}=1$ region) it is possible to determine the radiative saturation current density $\left(J_{01}\right)$, and these results are shown in Fig. 8. For the produced DJ cells, with the decrease of $\mathrm{C}_{r}$ (and the increase in reflectance) the $J_{01}$ values also decrease. This irrefutably shows an improvement in re-absorbtion of emitted photons generated by band-to-band recombination [22,25].

The external quantum efficiencies (EQE) of these devices, shown in Fig. 9, confirm that the mild increase in the $J_{s c}$ in the DJ devices is due to the increased reflection of the incident light. Most of the incident light with shorter wavelengths is absorbed before reaching the rear layers and no differences in the spectrum are expected in this region, but for wavelengths above $700 \mathrm{~nm}$, the EQE of the cells clearly increases.

Miller et al. [16] have modeled the effect that the rear mirror reflectance has on the cell parameters of a $3 \mu \mathrm{m}$ thick GaAs solar cell in the absence of non-radiative recombination. The model predicts a more than linear increase in $V_{o c}$ and a linear increase in $J_{s c}$ as the reflectance approaches $90 \%$. In order to facilitate the comparison between the results from the model and those from solar cells produced in this study, the earlier approximated $\mathrm{R}_{\text {cell }}$ value for each configuration is related to its $V_{o c}$ and $J_{s c}$ in Fig. 10. For easy comparison, the curves from the

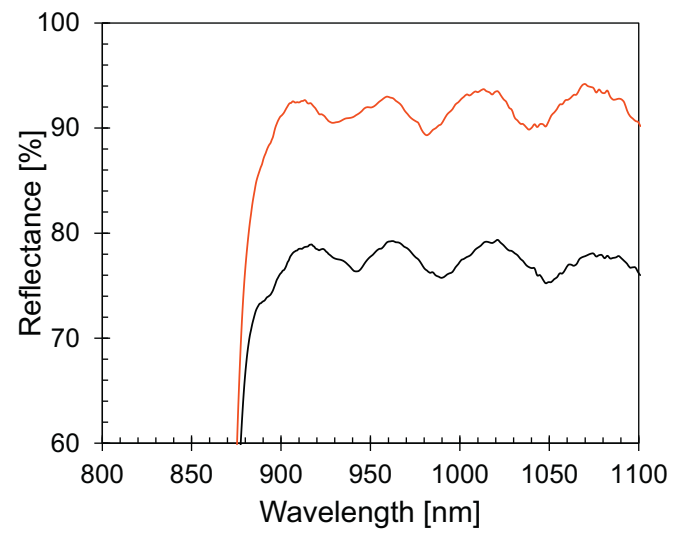

(b)

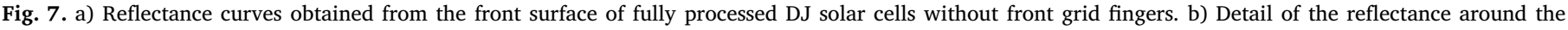
bandgap wavelength. 
Table 1

Illuminated IV parameters of both SJ and DJ solar cells with different rear surface contact fractions.

\begin{tabular}{|c|c|c|c|c|c|c|}
\hline & \multicolumn{3}{|l|}{ SJ devices } & \multicolumn{3}{|l|}{ DJ devices } \\
\hline & $J_{s c}$ & $V_{o c}$ & FF & $J_{s c}$ & $V_{o c}$ & $\mathrm{FF}$ \\
\hline $\mathrm{C}_{r}[\%]$ & $\pm 0.06\left[\frac{\mathrm{mA}}{\mathrm{cm}^{2}}\right]$ & $\pm 2[\mathrm{mV}]$ & $\pm 0.3[\%]$ & $\pm 0.06\left[\frac{\mathrm{mA}}{\mathrm{cm}^{2}}\right]$ & $\pm 2[\mathrm{mV}]$ & $\pm 0.3[\%]$ \\
\hline 100 & 24.17 & 1006 & 85.0 & 24.34 & 1050 & 85.8 \\
\hline 50 & - & - & - & 24.23 & 1053 & 85.6 \\
\hline 30 & 24.14 & 1000 & 84.4 & 24.43 & 1055 & 85.5 \\
\hline 10 & 24.15 & 0992 & 83.6 & 24.46 & 1058 & 82.1 \\
\hline
\end{tabular}

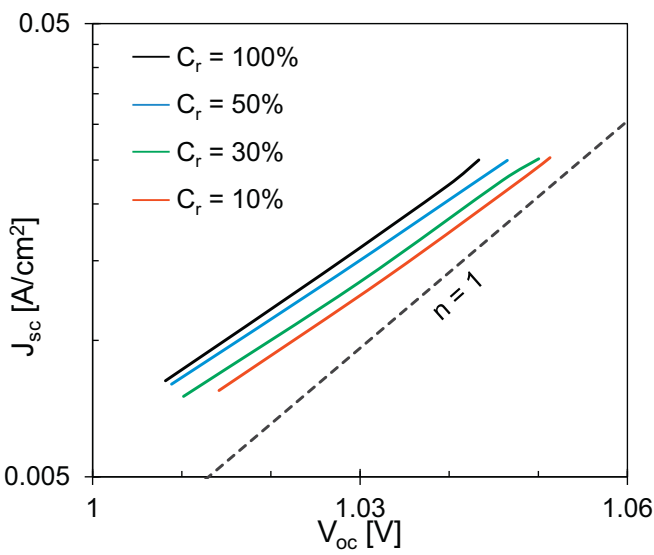

(a)

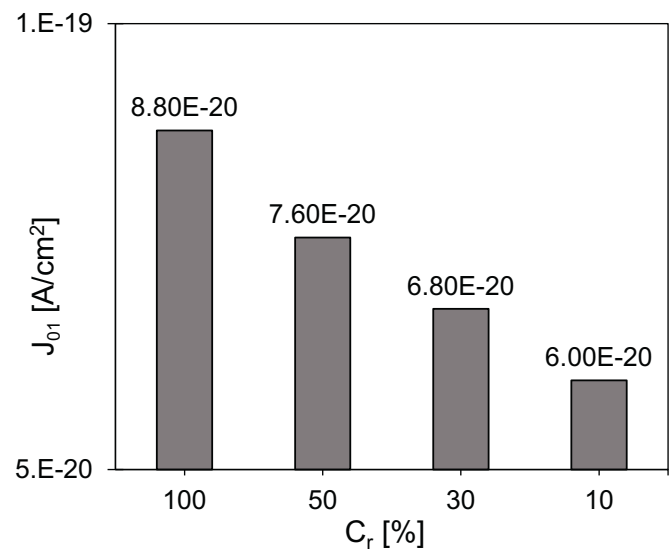

(b)

Fig. 8. a) $J_{s c}-V_{o c}$ curves measured at different light intensities of the DJ devices with different $\mathrm{C}_{r}$ and b) the calculated $J_{01}$ of each device.

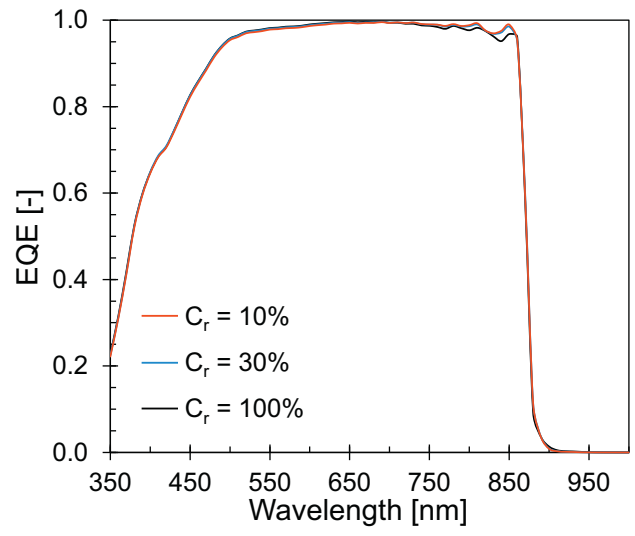

(a)

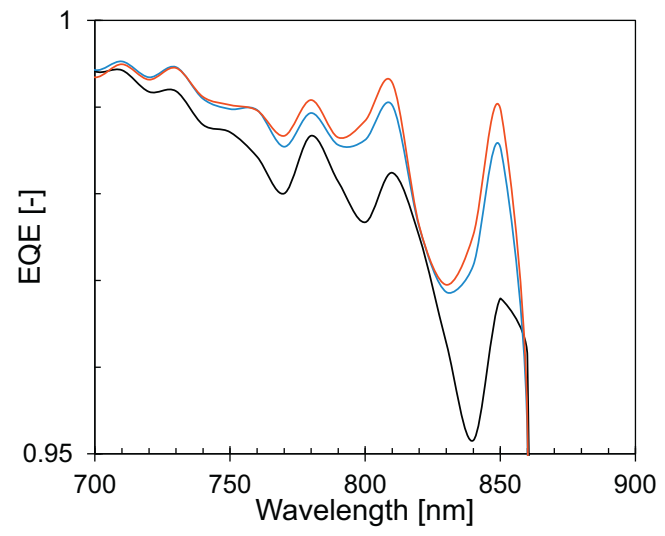

(b)

Fig. 9. a) External quantum efficiency of the DJ samples with different $\mathrm{C}_{r}$. b) Detail of the curve at the longer wavelength region.

literature are (on a different scale) also depicted in the same graphs. The obvious differences in the absolute $V_{o c}$ and $J_{s c}$ values derived from the model reported in literature and the values obtained in the here reported experiments are due to the fact that the model represents a simplification of the actual situation. The model, for example, neglects the reflection of light at the ARC and grid contacts of the cell and assumes the total absence of non-radiative recombination. Nevertheless, the obtained trends for the produced cells are similar to those following from numerical simulations, providing experimental proof of concept of this relationship.

\section{Conclusions and outlook}

Reemitted photons by band-to-band recombination in GaAs solar cells have a wavelength that varies from 840 to $870 \mathrm{~nm}$. In this region, the rear contact layer in thin-film GaAs solar cells absorbs a relevant fraction of photons, that therefore do not contribute to the solar cell performance. Both theoretical and experimental results show that compared to the use of a Au mirror directly on the BSF of the cell a further improved reflectance can be obtained by the application of an intermediate $\mathrm{ZnS}$ or $\mathrm{MgF}_{2}$ layer. Based on these results an approach comprising partial removal of the $\mathrm{p}$-GaAs contact layer and replacement by deposition of $\mathrm{ZnS}$ was developed and tested in both shallow junction and deep junction solar cell geometries. The calculated total reflectance at the active layers of these cells increases from $63.5 \%$ in the original structure $\left(C_{r}=100 \%\right)$, up to $93.2 \%$ with the new design $\left(C_{r}=10 \%\right)$.

In thin-film SJ devices the non-radiative saturation current density $\left(J_{02}\right)$ is higher and no positive effects on the cell performance are 


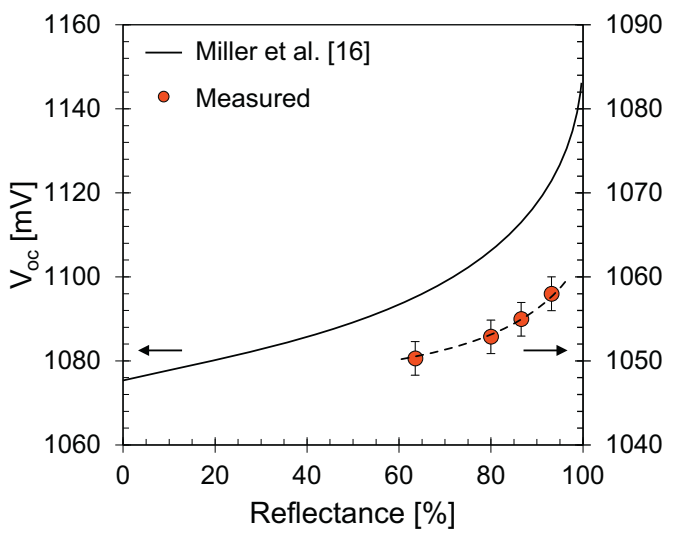

(a)

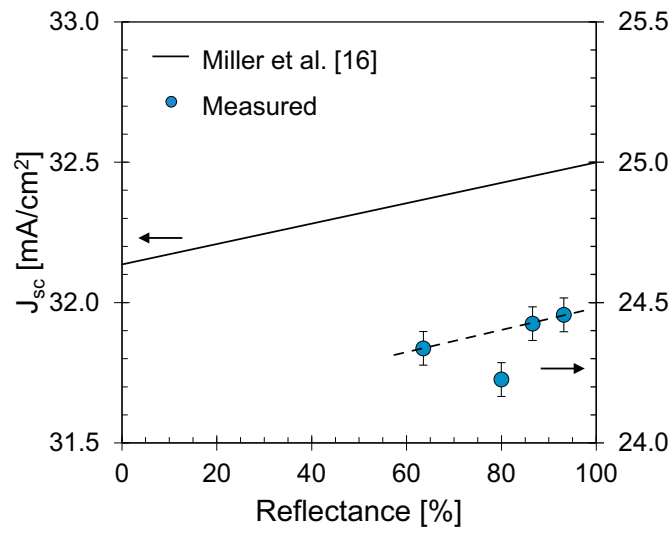

(b)

Fig. 10. Measured a) $V_{o c}$ and b) $J_{s c}$ of the DJ solar cells related to the respective average reflectance of the processed cell $\left(\mathrm{R}_{\text {device }}\right)$. The obtained trend in both parameters is similar to that predicted in the literature.

apparent by this approach. However, with the obtained increase in reflectance, the illuminated IV parameters of DJ solar cells improve, and the radiative saturation current density $\left(J_{01}\right)$ decreases. This demonstrates an increase in photon recycling and reaffirms the importance of the rear mirror reflectance in the design of thin-film GaAs solar cells.

The results of this study experimentally confirm previously reported theoretical calculations that relate the reflectance of the rear mirror and the solar cell parameters. Furthermore, the technique developed in this work provides a clear reduction of $J_{01}$ without any required changes to the growth structures of the solar cell. Therefore, with further reduction of the non-radiative losses and an optimized rear and front contact geometries, patterning the rear contact represents a viable approach to achieve efficiencies closer to the theoretical limit.

\section{Acknowledgments}

The authors acknowledge financial support from the Brazilian National Council for Scientific and Technological Development, under the program Science Without Border, project 233259/2014-7, and from the European Union's Horizon 2020 research and motivation program, under grant agreement 687253 TFQD (http://tfqd.eu).

\section{References}

[1] M. Konagai, M. Sugimoto, K. Takahashi, High efficiency GaAs thin film solar cells by peeled film technology, J. Cryst. Growth 45 (C) (1978) 277-280, http://dx.doi. org/10.1016/0022-0248(78)90449-9.

[2] E. Yablonovitch, T. Gmitter, J.P. Harbison, R. Bhat, Extreme selectivity in the liftoff of epitaxial GaAs films, App. Phys. Lett. 51 (26) (1987) 2222-2224, http://dx. doi.org/10.1063/1.98946.

[3] M.M.A.J. Voncken, J.J. Schermer, A.T.J. van Niftrik, G.J. Bauhuis, P. Mulder, P.K. Larsen, T.P.J. Peters, B. de Bruin, A. Klaassen, J.J. Kelly, Etching AlAs with HF for epitaxial lift-off applications, J. Electrochem. Soc. 151 (5) (2004) G347 http://jes.ecsdl.org/cgi/doi/10.1149/1.1690293http://dx.doi.org/10.1149/1. 1690293.

[4] M.M.A.J. Voncken, J.J. Schermer, G.J. Bauhuis, P. Mulder, P.K. Larsen, Multiple release layer study of the intrinsic lateral etch rate of the epitaxial lift-off process, Appl. Phys. A: Mater. Sci. Process. 79 (7) (2004) 1801-1807, http://dx.doi.org/10. 1007/s00339-003-2100-1.

[5] G.J. Bauhuis, J.J. Schermer, P. Mulder, M.M.A.J. Voncken, P.K. Larsen, Thin film GaAs solar cells with increased quantum efficiency due to light reflection, Sol. Energy Mater. Sol. Cells 83 (1) (2004) 81-90, http://dx.doi.org/10.1016/j.solmat. 2003.11.030.

[6] J.J. Schermer, P. Mulder, G.J. Bauhuis, M.M.A.J. Voncken, J. Van Deelen, E. Haverkamp, P.K. Larsen, Epitaxial lift-off for large area thin film III/V devices, Phys. Status Solidi 202 (4) (2005) 501-508, http://dx.doi.org/10.1002/pssa. 200460410.

[7] J.J. Schemer, P. Mulder, G.J. Bauhuis, P.K. Larsen, G. Oomen, E. Bongers, Thinfilm GaAs epitaxial lift-off solar cells for space applications, Prog. Photovolt. Res. Appl. 13 (7) (2005) 587-596, http://dx.doi.org/10.1002/pip.616.

[8] G.J. Bauhuis, P. Mulder, E.J. Haverkamp, J.J. Schermer, E. Bongers, G. Oomen,
W. Köstler, G. Strobl, Wafer reuse for repeated growth of III-V solar cells, Prog. Photovolt. Res. Appl. 18 (3) (2010) 155-159, http://dx.doi.org/10.1002/pip.930.

[9] F.L. Wu, S.L. Ou, R.H. Horng, Y.C. Kao, Improvement in separation rate of epitaxial lift-off by hydrophilic solvent for GaAs solar cell applications, Sol. Energy Mater. Sol. Cells 122 (2014) 233-240, http://dx.doi.org/10.1016/j.solmat.2013. 12.013.

[10] C.L. Stender, J. Adams, V. Elarde, T. Major, H. Miyamoto, M. Osowski, N. Pan, R. Tatavarti, F. Tuminello, A. Wibowo, C. Youtsey, G. Ragunathan, Flexible and lightweight epitaxial lift-off GaAs multi-junction solar cells for portable power and UAV applications, 2015 IEEE 42nd Photovoltaic Specialist Conference, PVSC 2015, 2015, pp. 8-11, , http://dx.doi.org/10.1109/PVSC.2015.7356137.

[11] X. Li, P.C. Li, L. Ji, C. Stender, S.R. Tatavarti, K. Sablon, E.T. Yu, Integration of subwavelength optical nanostructures for improved antireflection performance of mechanically flexible GaAs solar cells fabricated by epitaxial lift-off, Sol. Energy Mater. Sol. Cells 143 (2015) 567-572, http://dx.doi.org/10.1016/j.solmat.2015. 08.006.

[12] M.A. Green, Y. Hishikawa, W. Warta, E.D. Dunlop, D.H. Levi, J. Hohl-Ebinger, A.W. Ho-Baillie, Solar cell efficiency tables (version 50), Prog. Photovolt. Res. Appl. 25 (7) (2017) 668-676, http://dx.doi.org/10.1002/pip.2909 arXiv:1303.4604.

[13] W. Shockley, H.J. Queisser, Detailed balance limit of efficiency of p-n junction solar cells, J. Appl. Phys. 32 (3) (1961) 510-519, http://dx.doi.org/10.1063/1. 1736034 arXiv:9809069v1.

[14] X. Wang, M.R. Khan, J.L. Gray, M.A. Alam, M.S. Lundstrom, Design of gaas solar cells operating close to the Shockley-Queisser limit, IEEE J. Photovoltaics 3 (2) (2013) 737-744, http://dx.doi.org/10.1109/JPHOTOV.2013.2241594.

[15] E.D.E. Kosten, J.H.J. Atwater, J. Parsons, A. Polman, H.A. Atwater, Highly efficient GaAs solar cells by limiting light emission angle, Light: Sci. Appl. 2 (1) (2013) 1-6, http://dx.doi.org/10.1038/1sa.2013.1.

[16] O.D. Miller, E. Yablonovitch, S.R. Kurtz, Intense internal and external fluorescence as solar cell approach the SQ efficiency limit, IEEE J. Photovoltaics 2 (3) (2012) 1-27, http://dx.doi.org/10.1109/JPHOTOV.2012.2198434.

[17] F. Cappelluti, G. Ghione, M. Gioannini, G. Bauhuis, P. Mulder, J. Schermer, M. Cimino, G. Gervasio, G. Bissels, E. Katsia, T. Aho, T. Niemi, M. Guina, D. Kim, J. Wu, H. Liu, Novel Concepts for High-Efficiency Lightweight Space Solar Cells, E3S Web Conf. 16, 2017, p. 03007, , http://dx.doi.org/10.1051/e3sconf/ 20171603007.

[18] N. Vandamme, H.-L. Chen, A. Gaucher, B. Behaghel, A. Lemaitre, A. Cattoni, C Dupuis, N. Bardou, J.-F. Guillemoles, S. Collin, Ultrathin GaAs solar cells with a silver back mirror, IEEE J. Photovoltaics 5 (2) (2015) 565-570.

[19] S.M. Lee, A. Kwong, D. Jung, J. Faucher, R. Biswas, L. Shen, D. Kang, M.L. Lee, J. Yoon, High performance ultrathin GaAs solar cells enabled with heterogeneously integrated dielectric periodic nanostructures, ACS Nano 9 (10) (2015) 10356-10365, http://dx.doi.org/10.1021/acsnano.5b05585.

[20] W. Yang, J. Becker, Y.S. Kuo, J.J. Li, S. Liu, B. Landini, K. Campman, Y.H. Zhang, Ultra-thin GaAs single-junction solar cells integrated with an AlInP layer for reflective back scattering, Conf. Rec. IEEE Photovoltaic Spec. Conf. 203105 (2014) 3329-3332, http://dx.doi.org/10.1109/PVSC.2013.6745163.

[21] K. Nakayama, K. Tanabe, H.A. Atwater, Plasmonic nanoparticle enhanced light absorption in GaAs solar cells, Appl. Phys. Lett. 93 (12) (2008) 3-5, http://dx.doi. org/10.1063/1.2988288.

[22] G. Bauhuis, P. Mulder, Y.Y. Hu, J. Schermer, Deep junction III-V solar cells with enhanced performance, Phys. Status Solidi 213 (8) (2016) 2216-2222, http://dx. doi.org/10.1002/pssa.201532903.

[23] J.E. Parrott, Radiative recombination and photon recycling in photovoltaic solar cells, Sol. Energy Mater. Sol. Cells 30 (3) (1993) 221-231, http://dx.doi.org/10. 1016/0927-0248(93)90142-P.

[24] G.B. Lush, B-coefficient in n-type GaAs, Solar Energy Materials and Solar Cells 93 (8) (2009) 1225-1229, http://dx.doi.org/10.1016/j.solmat.2009.01.020.

[25] M.P. Lumb, M.A. Steiner, J.F. Geisz, R.J. Walters, Incorporating photon recycling 
into the analytical drift-diffusion model of high efficiency solar cells, J. Appl. Phys. 116 (19) (2014), http://dx.doi.org/10.1063/1.4902320.

[26] B.M. Kayes, H. Nie, R. Twist, S.G. Spruytte, F. Reinhardt, I.C. Kizilyalli, G.S. Higashi, 27.6\% conversion efficiency, a new record for single-junction solar cells under 1 sun illumination, Conf. Rec. IEEE Photovoltaic Spec. Conf. (2011) 000004-000008, http://dx.doi.org/10.1109/PVSC.2011.6185831.

[27] V. Ganapati, M.A. Steiner, E. Yablonovitch, The voltage boost enabled by luminescence extraction in solar cells, IEEE J. Photovoltaics 6 (4) (2016) 801-809, http://dx.doi.org/10.1109/JPHOTOV.2016.2547580.

[28] M.A. Steiner, J.F. Geisz, I. García, D.J. Friedman, A. Duda, S.R. Kurtz, Optical enhancement of the open-circuit voltage in high quality GaAs solar cells, J. Appl. Phys. 113 (123109) (2013), http://dx.doi.org/10.1063/1.4798267.
[29] S.T. Hwang, S. Kim, H. Cheun, H. Lee, B. Lee, T. Hwang, S. Lee, W. Yoon, H.M. Lee, B. Park, Bandgap grading and Al0.3Ga0.7As heterojunction emitter for highly efficient GaAs-based solar cells, Sol. Energy Mater. Sol. Cells 155 (2016) 264-272, http://dx.doi.org/10.1016/j.solmat.2016.06.009.

[30] SOPRA n-k database http://www.sspectra.com/sopra.html.

[31] E.F. Schubert, Light-Emitting Diodes: 2nd edition, Cambridge University Press, 2006, http://dx.doi.org/10.1017/CBO9780511790546.

[32] P. Espinet-González, I. Rey-Stolle, M. Ochoa, C. Algora, I. García, E. Barrigón, Analysis of perimeter recombination in the subcells of $\mathrm{GaInP} / \mathrm{GaAs} / \mathrm{Ge}$ triplejunction solar cells, Prog. Photovolt: Res. Appl. 23 (2015) 874-882, http://dx.doi. org/10.1002/pip.2501. 